\title{
Improvement of Charge-Discharge Characteristics of the Mg-Ni Powder Electrodes at $55^{\circ} \mathrm{C}$
}

\author{
Kuan-Jen Chen, ${ }^{1}$ Fei-Yi Hung, ${ }^{2}$ Truan-Sheng Lui, ${ }^{2}$ and Ren-Syuan Xiao ${ }^{2}$ \\ ${ }^{1}$ The Instrument Center, National Cheng Kung University, Tainan 701, Taiwan \\ ${ }^{2}$ Department of Materials Science and Engineering, National Cheng Kung University, Tainan 701, Taiwan \\ Correspondence should be addressed to Fei-Yi Hung; fyhung@mail.ncku.edu.tw
}

Received 17 September 2013; Revised 15 November 2013; Accepted 18 November 2013

Academic Editor: Ting-Jen Hsueh

Copyright (C) 2013 Kuan-Jen Chen et al. This is an open access article distributed under the Creative Commons Attribution License, which permits unrestricted use, distribution, and reproduction in any medium, provided the original work is properly cited.

\begin{abstract}
Magnesium-nickel (Mg-Ni) powders are used as the anode materials for secondary lithium (Li) ion batteries. Mg-Ni powders with ratios of $1: 1(\mathrm{Mg}: \mathrm{Ni})$ are prepared and their structure and electrochemical behavior at room temperature and $55^{\circ} \mathrm{C}$ are investigated. The results show that adding $\mathrm{Ni}$ powders to $\mathrm{Mg}$ powders can reduce the charge-discharge capacities and improve cycling life. In charge-discharge cycle testing at $55^{\circ} \mathrm{C}$, the Li ion concentration gradually increased with increasing the duration of electrochemical reactions, indicating that the charge-discharge capacities increase with increment of cycling number. The formation of a solid electrolyte interface (SEI) layer restrains $\mathrm{Mg}$ ions from dissolving into the electrolyte and thus improves the charge-discharge capacities at high temperature.
\end{abstract}

\section{Introduction}

Magnesium (Mg) was used as a negative electrode in lithium (Li) ion secondary batteries due to its high theoretic capacity [1]. However, pure metal electrodes have a serious problem of volume expansion during cycling that resulted in poor cycling life. Adding poor-activity elements into a pure metal matrix reduces the volume expansion of an electrode. Studies on alloy electrode materials have focused on Sn- [2], Si[3], and Mg-based alloys [4, 5]. Of the electrodes based on these alloys, Mg-based ones are one of the potential material in Li-ion battery applications. Many studies have indicated that $\mathrm{Mg}$-based alloy electrode, such as $\mathrm{Mg}-\mathrm{Li}, \mathrm{Mg}-\mathrm{C}$, and $\mathrm{Mg}-\mathrm{Ni}$ alloys, can enhance battery performance via various electrochemical mechanisms [4, 6-8]. Adding Li into Mg can enhance the efficiency of lithiation and delithiation [9] and $\mathrm{Mg}-\mathrm{C}$ alloys can restrain the growth of the solid electrolyte interface (SEI) layer [4]. In the present study, Mg-Ni powder electrodes were fabricated to suppress the volume change of the electrode and increase oxidation resistance.

$\mathrm{Mg}-\mathrm{Ni}$ material is a typical active/nonactive alloy system that can effectively suppress the volume expansion and improve battery cycling life. Many researchers have prepared
Mg-Ni alloys using the mechanical grinding method [10, 11]. However, the proportion of $\mathrm{Mg}$ to $\mathrm{Ni}$ is not easy to control, and $\mathrm{Mg}$-Ni alloys with excessive $\mathrm{Ni}$ have reduced chargedischarge capacity [12]. In addition, $\mathrm{Mg}$ easily oxidized to form $\mathrm{MgO}$ phases during mechanical milling [13]. The formation of $\mathrm{MgO}$ phases may degrade the cycling performance of batteries. In this study, Mg powder was directly mixed with $\mathrm{Ni}$ powder in a glove box. Because the particle size of Mg powder and that of Ni powder is very different, alloying effect prevents oxidation problems [14].

This method is simple and the composition ratio of elements can be easily controlled. Portable electronic devices generate heat during operation, which affects Li-ion battery performance. Thus, the charge-discharge characteristics of batteries at high temperature are an important issue. However, few studies have investigated the thermal effects on the charge-discharge characteristics of $\mathrm{Mg}-\mathrm{Ni}$ compound electrodes.

This study synthesizes $\mathrm{Mg}-\mathrm{Ni}$ powders and investigates the structural and electrochemical characteristics of $\mathrm{Mg}-\mathrm{Ni}$ alloy electrodes at room temperature and $55^{\circ} \mathrm{C}$. The relations of electrical resistance and electrochemical reaction cycles of $\mathrm{Mg}-\mathrm{Ni}$ electrodes at high temperature are derived. The metal 


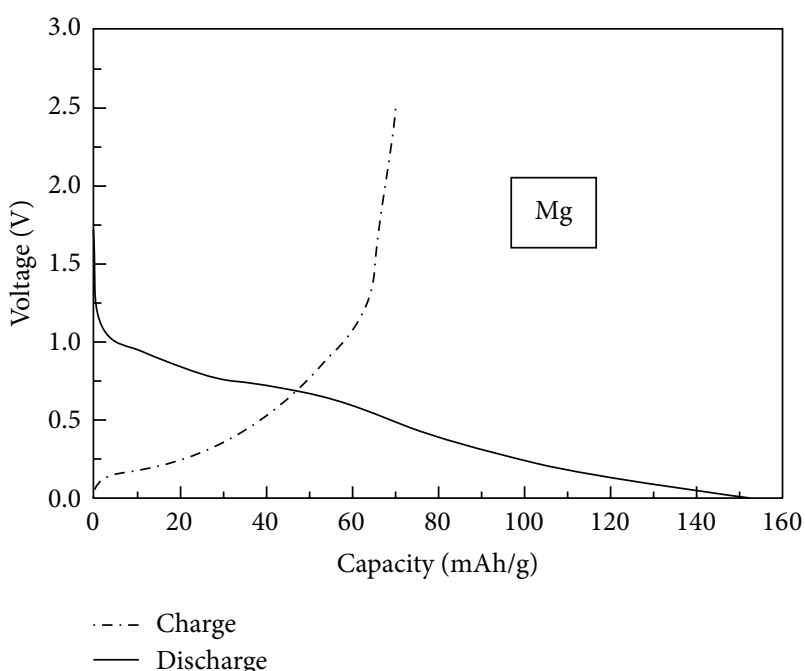

(a)

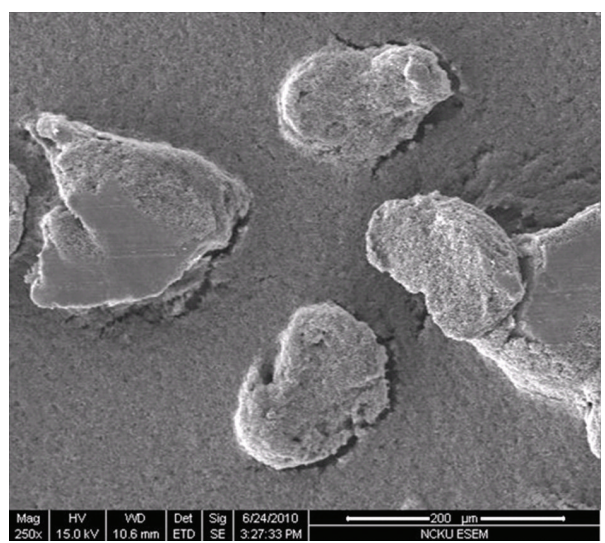

(b)

FIgURE 1: The electrode of pure Mg powder: (a) charge-discharge curve of the first cycle and (b) surface characteristic.

ion content in the electrolyte is determined to understand the influence of heat and clarify the contribution of Ni addition.

\section{Experimental Procedures}

An insufficient Ni powder concentration does not lead to the generation of a sufficient passivation layer around the $\mathrm{Mg}$ powder. An excess of Ni powder might cause more compound phases, resulting in degraded deterioration of chargedischarge capacities [6]. Therefore, magnesium-nickel (Mg$\mathrm{Ni})$ compound powders were prepared by mixing of $\mathrm{Mg}(\Phi$ $150 \sim 180 \mu \mathrm{m})$ and $\mathrm{Ni}(\Phi 2 \sim 5 \mu \mathrm{m})$ powders in weight ratios of $\mathrm{Mg}: \mathrm{Ni}=1: 1$ and then milled with a rotation rate of $600 \mathrm{rpm}$ using a planetary micromill (FRITSCH GmbH, PULVERISETTE 7) to acquire alloying effect. The compound powders are designated according to the weight ratio of $\mathrm{Mg}$ to $\mathrm{Ni}$ as MN11.

The Mg-Ni compound powders were uniformly stirred with carbon black (15wt.\%) and polyvinylidene fluoride (PVDF, 15 wt.\%) and then coated on copper (Cu) foils. And then, the electrodes were dried in an oven at $120^{\circ} \mathrm{C}$ for 1 hour. The Mg-Ni powder electrodes were cut into disks (13 $\mathrm{mm}$ in diameter and about $200 \mu \mathrm{m}$ in thickness) and Li foil was used as a counter electrode (positive electrode). One M LiPF6, ethylene carbonate (EC) and, diethyl carbonate (DEC) were used as an electrolyte and the volume ratio of EC to DEC was 1.

This study measured the surface characteristics of powder electrodes using high-resolution scanning electron microscopy (HR-SEM, HITACHI/SU8000). The electrochemical testing was performed with a lithium battery testing (LBT) cell using the battery automatic tester (BAT-750B). The cells were tested at a constant current of $20 \mathrm{~mA} \cdot \mathrm{g}^{-1}$. Cyclic voltammetry (CV) was used to investigate the cycling efficacy with electrochemical impedance spectroscopy (EIS,
PARSTAT 2273). The electric potential was limited to the range $0 \sim 2 \mathrm{~V}$ and the velocity of scanning was $0.05 \mathrm{mV} \cdot \mathrm{s}^{-1}$. In addition, the resistances of powder electrodes after the electrochemical testing were measured using a 4-point probe. Finally, inductively coupled plasma-mass spectrometry (ICPMS, HEWLETT PACKARD 4500) was used to determine the metal ion content in the electrolyte.

\section{Results and Discussions}

3.1. Charge-Discharge Characteristics of the $M g$-Ni Electrodes at Room Temperature. Figure 1(a) shows the voltage profile for the first cycle of a pure $\mathrm{Mg}$ powder electrode at room temperature. The charge-discharge curve has a plateau at a voltage of $1.0 \sim 0.75 \mathrm{~V}$, which is associated with the formation of the SEI layer [6]. The initial discharge capacity of the $\mathrm{Mg}$ powder electrode $\left(151 \mathrm{mAh} \cdot \mathrm{g}^{-1}\right)$ was much lower than that of $\mathrm{Mg}$ film electrode $\left(2644 \mathrm{mAh} \cdot \mathrm{g}^{-1}\right)$ in our previous experiment, which is due to the surface oxidization and looseness of the Mg powder electrode. The surface characteristics of $\mathrm{Mg}$ powder electrode before charging and discharging is shown in Figure 1(b). Some cracks appear on the surface of the electrode, which allowed the Li ions to react with the $\mathrm{Cu}$ foil, resulting in degraded charge-discharge capacities. Although the $\mathrm{Mg}$ film electrode has good charge-discharge characteristics, the electrochemical reaction might be an explosion hazard due to its activity [1]. Adding Ni powder to $\mathrm{Mg}$ powder can promote structural compactness, which may improve the charge-discharge characteristics of a battery. Therefore, the Ni powder was mixed with $\mathrm{Mg}$ powder to form a compound phase around $\mathrm{Mg}$ powder to avoid intense electrochemical reaction.

Figure 2(a) shows the initial charge-discharge profiles of the MN11 powder electrodes at room temperature. Compared to the initial discharge capacity of the pure $\mathrm{Mg}$ powder 


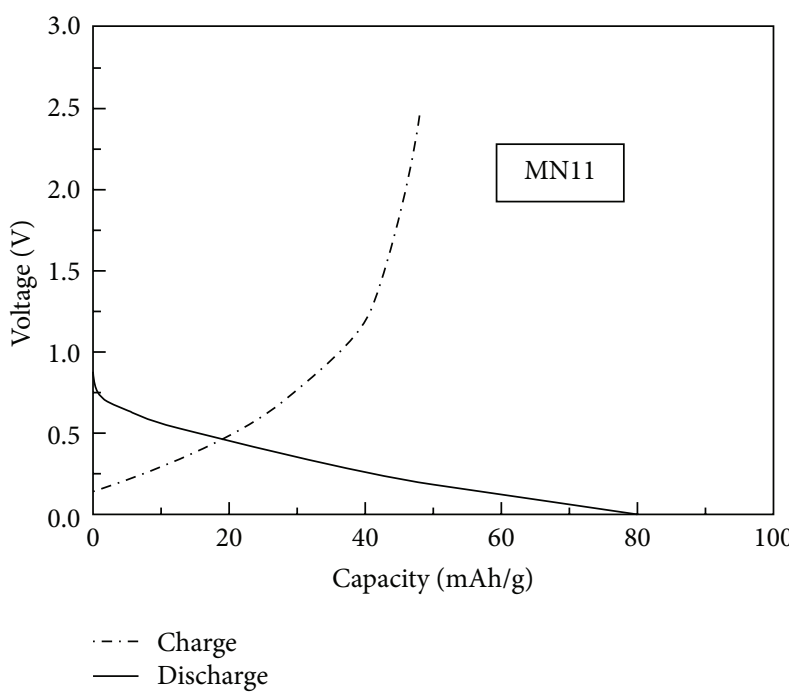

(a)

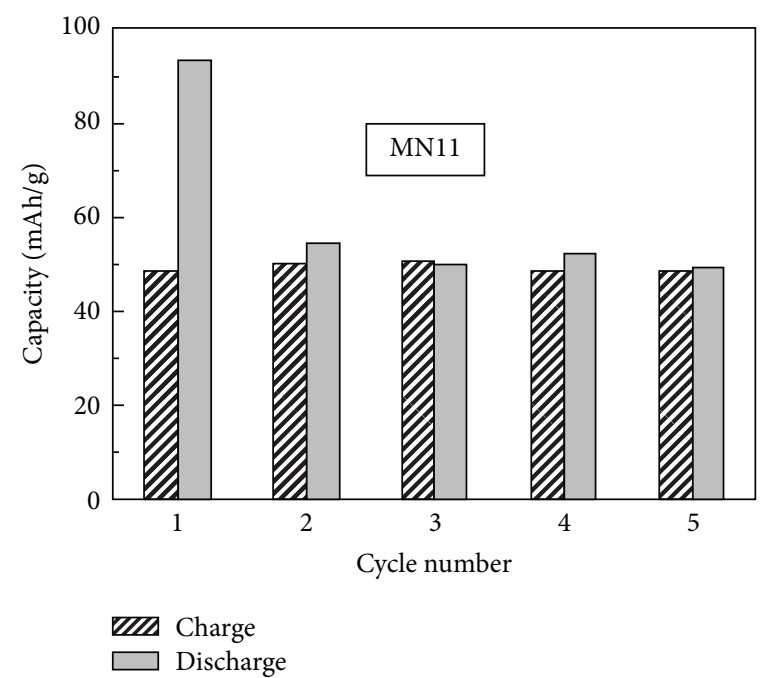

(b)

FIGURE 2: MN11 compound powders at room temperature: (a) charge-discharge curves of the first cycle and (b) charge-discharge capacities as a function of cycle number.

electrode, that of MN11 powder electrodes was low, indicating that $\mathrm{Mg}$ activity was restrained by $\mathrm{Ni}$ [15]. Previous studies $[6,16]$ have indicated that the $\mathrm{Mg}_{2} \mathrm{Ni}$ and $\mathrm{MgNi}_{2}$ alloy phases generated in the $\mathrm{Mg}-\mathrm{Ni}$ alloy system can restrain volume expansion and thus improve the cycling life of a battery. There is a voltage plateau at $0.2 \sim 0.5 \mathrm{~V}$, indicating that the $\mathrm{Li}$ ions became embedded in the positive electrode (Li foil). The potential voltage of $0.5 \sim 1.25 \mathrm{~V}$ was associated with some Li ions moving out from the electrode matrix. The charge-discharge capacities as a function of cycle number for the MN11 powder electrode at the room temperature are shown in Figure 2(b). In addition to having higher initial discharge capacity, MN11 electrode had stable charge-discharge characteristics in the subsequent electrochemical reactions. This result may attribute to the formation of the SEI layer in the initial charge-discharge reaction [17]. Generally, the charge-discharge characteristics of battery could gradually deteriorate with cycling [18]. However, the proposed MN11 electrode still maintained stable charge-discharge capacities due to alloying effect reduced oxidation problem.

3.2. High-Temperature Cycling Performance. In general, the cycle life of a battery operated in a high-temperate environment deteriorates quickly. In order to understand the effects of heat treatment on the cycling performance of batteries, the charge-discharge characteristics at $55^{\circ} \mathrm{C}$ were tested. The initial discharge curve of the MN11 electrode at $55^{\circ} \mathrm{C}$ has two plateaus, at voltages of 0.9 and $0.2 \mathrm{~V}$, respectively (Figure 3(a)). The plateau at $0.9 \mathrm{~V}$ only appears in the initial discharge curve, indicating that the SEI layer formed [17]. The voltage plateau at $0.2 \sim 0 \mathrm{~V}$ appears in every discharge curve and is attributed to the potential of lithiation and delithiation [8]. In a high temperature environment, the voltage plateau at $0.2 \sim 0 \mathrm{~V}$ was longer compared to that of the $\mathrm{Mg}$-Ni electrode at room temperature. This result is due to more $\mathrm{Li}$ ions becoming embedded into the electrode matrix at $55^{\circ} \mathrm{C}$ due to the high temperature increasing the kinetic energy and chemical activity. Figure 3(b) clearly shows that the cycling capacities of the battery increased with increasing cycle number. This reveals that the Li foil (positive electrode) could more easily react with the electrolyte to liberate more $\mathrm{Li}$ ions in the cell at $55^{\circ} \mathrm{C}$. Also, the heat affected the diffusion rate of $\mathrm{Li}$ ions in the cell. Although a high temperature environment enhances capacity, the cycling performance of the battery deteriorates more quickly. Nevertheless, the Mg$\mathrm{Ni}$ powder electrode had good high temperature cycling characteristics. In fact, some $\mathrm{Li}$ ions did not participate in the reaction at room temperature. At $55^{\circ} \mathrm{C}$, the heat enhanced the kinetic energy and chemical activity, promoting more $\mathrm{Li}$ ions to participate in the reaction and caused the diffusion rate of $\mathrm{Li}$ ions to increase with increasing the duration of electrochemical reactions.

To investigate the thermal effect on the electrochemical reaction, the cyclic voltammetry $(\mathrm{CV})$ of the MN11 electrode at $55^{\circ} \mathrm{C}$ is presented in Figure 4 . There is a peak at $0.25 \mathrm{~V}$ in the charge curve, indicating that a large number of Li ions inserted into the MN11 electrode. After the first cycle, the irreversible reaction is associated with the formation of the SEI layer [19]. With increasing the cycle number, the peak at $0.25 \mathrm{~V}$ gradually increased, indicating that cycle performance improved, which is consistent with Figure 3(b). In addition, the potential voltage shifted, which is related to the variation of the internal resistance of the powder electrode [20].

After 5 charge-discharge cycles, the surface characteristics of the MN11 electrode at room temperature (MN11$\mathrm{RT}$ ) and $55^{\circ} \mathrm{C}$ (MN11-HT) were recorded to clarify the growth behavior of the SEI layer (Figure 5). The surface morphology of the MN11-RT powder electrode shows many cracks (Figure 5(a)). The continuous lithiation and delithiation reactions caused a volume expansion of the electrode, resulting in the fracture of the SEI layer [21]. For the MN11HT electrode, the electrode surface has a dense SEI layer 


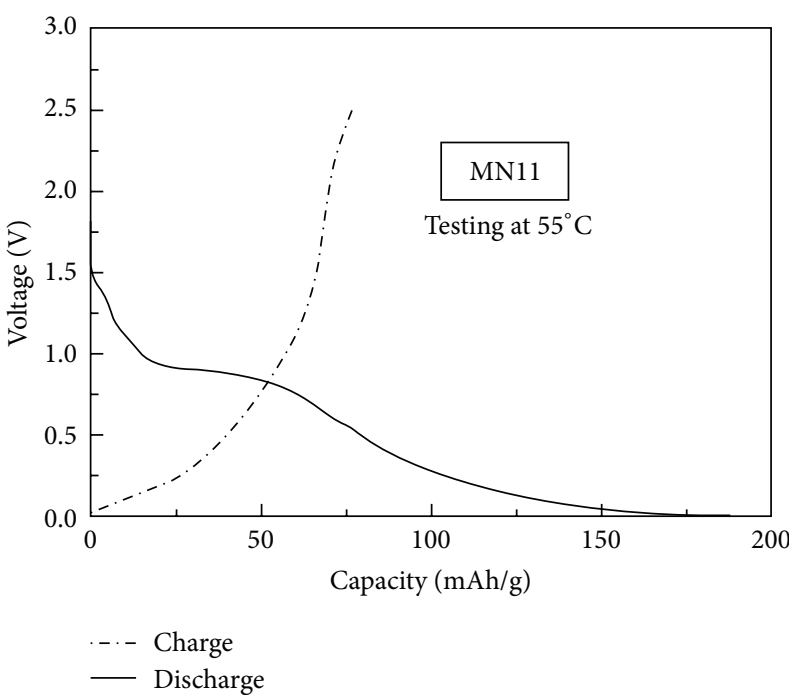

(a)

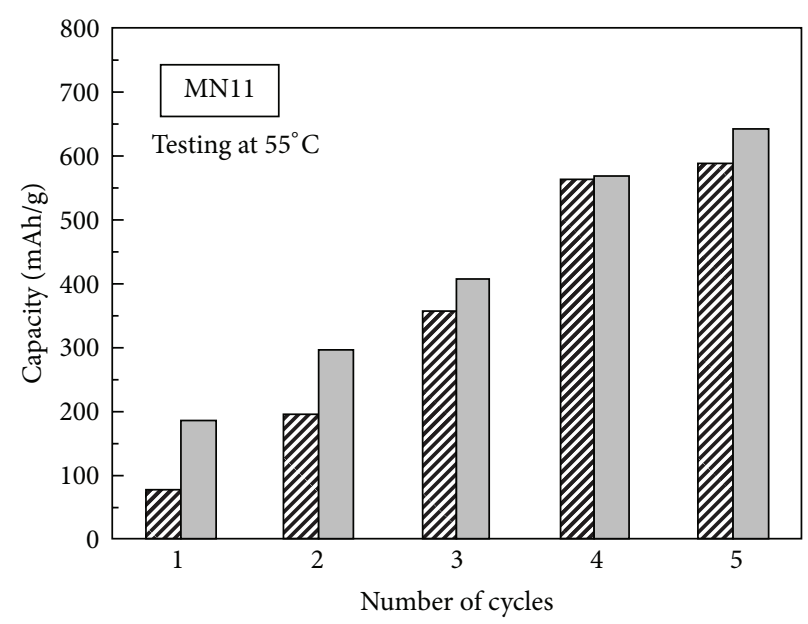

שII Charge Discharge

(b)

FIGURE 3: (a) Initial charge-discharge curves and (b) charge-discharge capacities as function of cycle number for MN11 compound electrode at $55^{\circ} \mathrm{C}$.

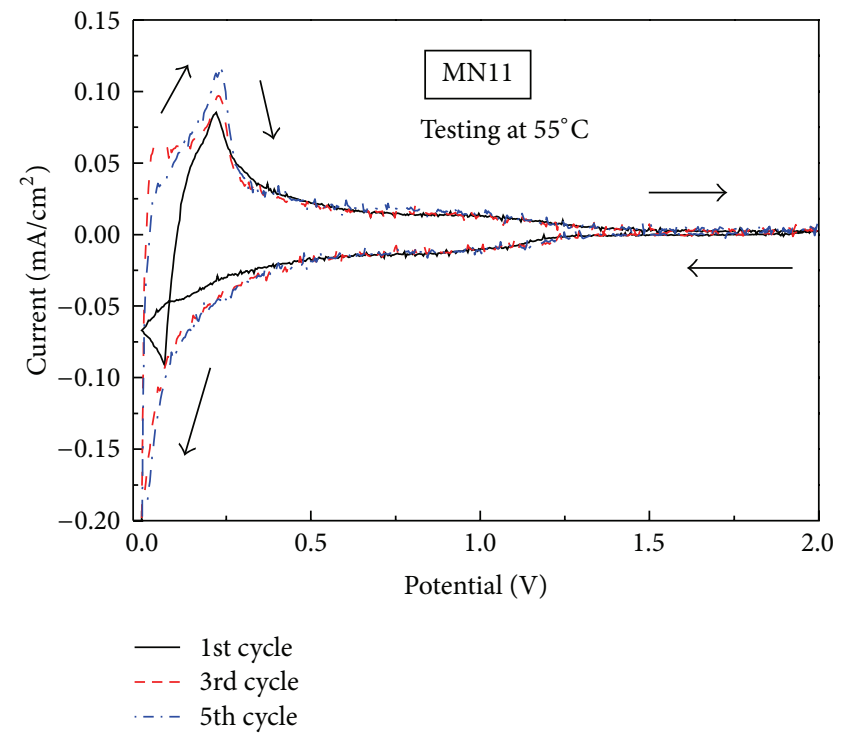

FIGURE 4: Cyclic voltammograms of MN11 electrode with $55^{\circ} \mathrm{C}$ measured for 5 cycles at scan rate of $0.05 \mathrm{mV} \mathrm{s}^{-1}$.

and fewer cracks (Figure 5(b)). The growth rate of the SEI layer was faster in the high temperature environment [22]; the electrode surface was covered with thicker SEI layer. As a result, the thicker SEI layer was more able to resist the volume expansion of the electrode.

In addition, the SEI structure might decompose during the electrochemical reaction at high temperature, as its thickness did not continuously increase. This explains the improved charge-discharge characteristics of the $\mathrm{Mg}-\mathrm{Ni}$ electrode at high temperature. The cracks may affect the resistance of the electrode. Therefore, the resistivity of MN11-RT
TABLE 1: The resistance value of the Mg-Ni electrode at room temperature (RT) and $55^{\circ} \mathrm{C}(\mathrm{HT})$ after different charge-discharge cycling.

\begin{tabular}{lccc}
\hline Sample & \multicolumn{3}{c}{ Resistivity $(\Omega * \mathrm{~cm})$} \\
& 1 st cycle & 3rd cycle & 5th cycle \\
\hline MN11-RT & $4.0 \times 10^{4}$ & $5.6 \times 10^{3}$ & $7.8 \times 10^{3}$ \\
MN11-HT & $2.1 \times 10^{4}$ & $2.2 \times 10^{3}$ & $1.7 \times 10^{3}$ \\
\hline
\end{tabular}

TABLE 2: The dissolution of metal ions concentration in an electrolyte for MN11 and pure Mg electrode.

\begin{tabular}{lcc}
\hline \multirow{2}{*}{ Sample } & \multicolumn{2}{c}{ Ion concentration $\left(\mu \mathrm{g} \cdot \mathrm{mL}^{-1}\right)$} \\
& $\mathrm{Mg}$ & $\mathrm{Ni}$ \\
\hline $\mathrm{MN11}$ & 2.760 & 0.469 \\
$\mathrm{Mg}$ & 5.709 & $\mathrm{~N} / \mathrm{A}$ \\
\hline
\end{tabular}

and MN11-HT electrodes at various charge-discharge cycles were measured (Table 1). The resistance of the MN11-RT electrode decreased from the first to the third cycles and then increased. The main reason was that the intense volume expansion of the electrode increased the number of cracks. In contrast, the resistance of the MN11-HT electrode continuously decreased with increasing charge-discharge cycle. This result might be associated with the thicker SEI layer restraining the volume expansion, which is consistent with the $\mathrm{CV}$ results (Figure 5(b)).

In order to clarify the thermal effects on ion liberation behavior, the electrolyte was examined using ICP-MS (Table 2). The electrolyte of the MN11-HT electrode had fewer $\mathrm{Mg}$ ions $\left(2.760 \mu \mathrm{g} \cdot \mathrm{mL}^{-1}\right)$ compared to the electrolyte of the $\mathrm{Mg}$ electrode $\left(5.709 \mu \mathrm{g} \cdot \mathrm{mL}^{-1}\right)$. This result indicates that adding $\mathrm{Ni}$ powder can reduce the liberation of $\mathrm{Mg}$ ions. 


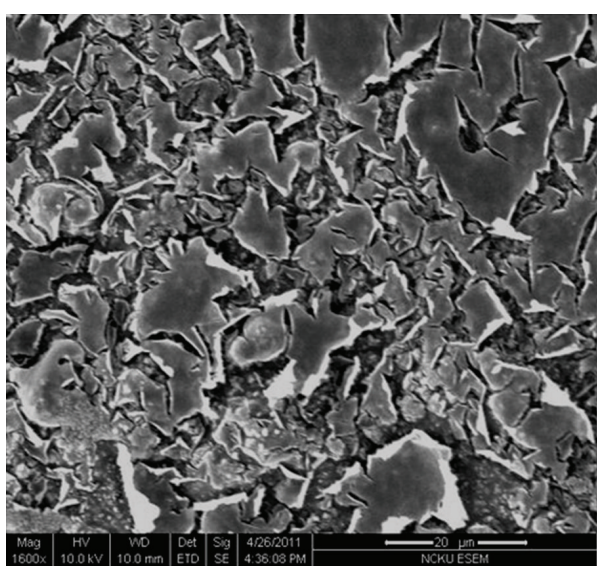

(a)

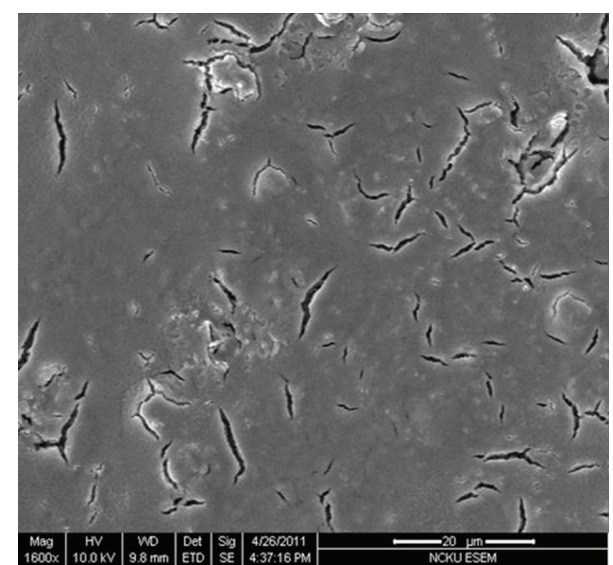

(b)

FIGURE 5: The surface characteristics of the solid electrolyte interface layer of MN11 electrode with (a) room temperature and (b) $55^{\circ} \mathrm{C}$ after 5 charge-discharge cycles.

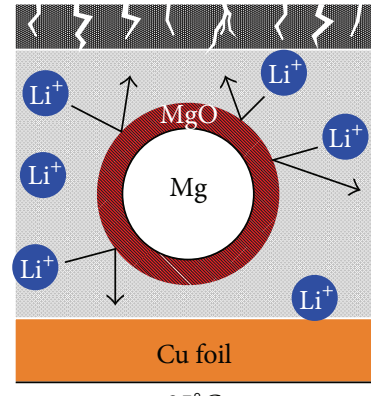

$25^{\circ} \mathrm{C}$

(a)

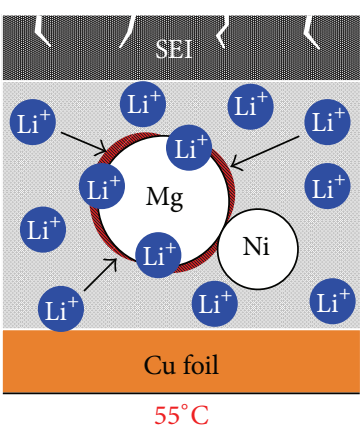

(b)

FIGURE 6: Schematic illustrations of pure $\mathrm{Mg}$ and the $\mathrm{Mg}-\mathrm{Ni}$ electrode with the duration of the charge-discharge reactions.

In addition, the Mg-Li compound phases formed at high temperature, enhancing electrode's ability to resist fracture [23].

Schematic illustration of pure $\mathrm{Mg}$ and the Mg-Ni electrode with charge-discharge duration is shown in Figure 6. For the pure Mg electrode at the room temperature, the SEI layer was thinner and the volume expansion of the electrode was more obvious, resulting in serious cracks after the chargedischarge. In addition, $\mathrm{Mg}$ easily oxidized to form $\mathrm{MgO}$ phases, which decreased the activity of $\mathrm{Mg}$. The $\mathrm{MgO}$ phases prevented $\mathrm{Li}$ ions to react with $\mathrm{Mg}$ and thus degraded the charge-discharge efficiencies. Mg-Ni compound phases could restrain the activity of $\mathrm{Mg}$ and the volume expansion of electrode during the charge-discharge processes. Notably, a fewer $\mathrm{MgO}$ phases allowed $\mathrm{Li}$ ions to react with $\mathrm{Mg}$ more easily. At $55^{\circ} \mathrm{C}$, the heat increased the kinetic energy and chemical activity, making the Li ion concentration increase with increasing charge-discharge cycles. In addition, the growth rate of the SEI layer was faster, which reduced the crack density. The high temperature also caused the decomposition of the SEI layer, which prevented the SEI layer from increasing without bound. The $\mathrm{Mg}-\mathrm{Ni}$ electrode at $55^{\circ} \mathrm{C}$ has good charge-discharge capacities, making it suitable for Li-ion battery operation at high temperature.

\section{Conclusion}

Ni powders mixed with Mg powders were found to effectively suppress the activity of $\mathrm{Mg}$ and the volume expansion of the electrode due to the formation of a passivation layer and the existence of $\mathrm{Mg}-\mathrm{Ni}\left(\mathrm{Mg}_{2} \mathrm{Ni}\right.$ and $\left.\mathrm{MgNi}_{2}\right)$ alloy phases. Adding Ni powder reduced $\mathrm{Mg}$ dissolution without significantly degrading. At high temperature of $55^{\circ} \mathrm{C}$, the chargedischarge capacities and cycling performance of the $\mathrm{Mg}-\mathrm{Ni}$ alloy electrode were enhanced. The main reason was that the high temperature increased the kinetic energy and chemical activity, making the $\mathrm{Li}$ ion concentration increase with electrochemical reaction time. Additionally, the electrode at high temperature formed a thicker SEI layer, which resisted the volume expansion of the electrode. The decomposition of the SEI structure at high temperature caused the cycle life of the battery. The Mg-Ni alloy electrode is thus suitable for application in Li-ion batteries operated at high temperature.

\section{Acknowledgments}

The authors are grateful to the National Science Council (NSC) Instrument Center at the National Cheng Kung 
University (NCKU) and National Science Council, Taiwan, for financially supporting this study under Grant nos. 1012221-E-006-114.

\section{References}

[1] W.-J. Zhang, "A review of the electrochemical performance of alloy anodes for lithium-ion batteries," Journal of Power Sources, vol. 196, no. 1, pp. 13-24, 2011.

[2] A. R. Kamali and D. J. Fray, "Tin-based materials as advanced anode materials for lithium ion batteries: a review," Reviews on Advanced Materials Science, vol. 27, no. 1, pp. 14-24, 2011.

[3] X.-Y. Zhou, J.-J. Tang, J. Yang et al., "Effect of polypyrrole on improving electrochemical performance of silicon based anode materials," Electrochimica Acta, vol. 70, pp. 296-303, 2012.

[4] F.-Y. Hung, T.-S. Lui, R.-S. Xiao, Y.-W. Tseng, and C.-H. Wang, "Structural effects and charge-discharge characteristics of MgC/Mg-Li alloy thin film materials," Materials Transactions, vol. 52, no. 6, pp. 1127-1131, 2011.

[5] D. X. Cao, L. Wu, Y. Sun, G. Wang, and Y. Lv, "Electrochemical behavior of $\mathrm{Mg}-\mathrm{Li}, \mathrm{Mg}-\mathrm{Li}-\mathrm{Al}$ and $\mathrm{Mg}-\mathrm{Li}-\mathrm{Al}-\mathrm{Ce}$ in sodium chloride solution," Journal of Power Sources, vol. 177, no. 2, pp. 624-630, 2008.

[6] H. Kim, B. Park, H.-J. Sohn, and T. Kang, "Electrochemical characteristics of $\mathrm{Mg}-\mathrm{Ni}$ alloys as anode materials for secondary Li batteries," Journal of Power Sources, vol. 90, no. 1, pp. 59-63, 2000.

[7] C.-M. Park, Y.-U. Kim, H. Kim, and H.-J. Sohn, "Enhancement of the rate capability and cyclability of an $\mathrm{Mg}$ - $\mathrm{C}$ composite electrode for Li secondary batteries," Journal of Power Sources, vol. 158, no. 2, pp. 1451-1455, 2006.

[8] H. Kim, J. Choi, H.-J. Sohn, and T. Kang, "The insertion mechanism of lithium into $\mathrm{Mg} 2 \mathrm{Si}$ anode material for li-ion batteries," Journal of the Electrochemical Society, vol. 146, no. 12, pp. 4401-4405, 1999.

[9] R. Benedek and M. M. Thackeray, "Lithium reactions with intermetallic-compound electrodes," Journal of Power Sources, vol. 110, no. 2, pp. 406-411, 2002.

[10] H. Inoue, T. Ueda, S. Nohara, N. Fujita, and C. Iwakura, "Effect of ball-milling on electrochemical and physicochemical characteristics of crystalline Mg2Ni alloy," Electrochimica Acta, vol. 43, no. 14-15, pp. 2215-2219, 1998.

[11] R. A. Varin, T. Czujko, and J. Mizera, "Microstructural evolution during controlled ball milling of $(\mathrm{Mg} 2 \mathrm{Ni}+\mathrm{MgNi} 2)$ intermetallic alloy," Journal of Alloys and Compounds, vol. 350, no. 1-2, pp. 332-339, 2003.

[12] S. G. Zhang, Y. Hara, T. Morikawa, H. Inoue, and C. Iwakura, "Electrochemical and structural characteristics of amorphous $\operatorname{MgNix}(x>=1)$ alloys prepared by mechanical alloying," Journal of Alloys and Compounds, vol. 293, pp. 552-555, 1999.

[13] G. Liu, S. Xi, G. Ran, K. Zuo, P. Li, and J. Zhou, "A new phase MgNi3 synthesized by mechanical alloying," Journal of Alloys and Compounds, vol. 448, no. 1-2, pp. 206-209, 2008.

[14] M. Anik, G. Özdemir, N. Küükdeveci, and B. Baksan, "Effect of $\mathrm{Al}, \mathrm{B}, \mathrm{Ti}$ and $\mathrm{Zr}$ additive elements on the electrochemical hydrogen storage performance of $\mathrm{MgNi}$ alloy," International Journal of Hydrogen Energy, vol. 36, no. 2, pp. 1568-1577, 2011.

[15] S.-S. Lee, K.-W. Kim, B.-Y. Hur, T.-H. Nam, and H.-J. Ahn, "A study on the electrochemical properties of an $\mathrm{Mg}$-Ni based thin film electrode for a microbattery," Metals and Materials International, vol. 7, no. 3, pp. 265-268, 2001.
[16] R. A. Varin, T. Czujko, and J. Mizera, “The effect of MgNi2 intermetallic compound on nanostructurization and amorphization of Mg-Ni alloys processed by controlled mechanical milling," Journal of Alloys and Compounds, vol. 354, no. 1-2, pp. 281-295, 2003.

[17] C.-H. Wu, F.-Y. Hung, T.-S. Lui, and L.-H. Chen, "Microstructures and the charge-discharge characteristics of advanced AlSi thin film materials," Materials Transactions, vol. 51, no. 10, pp. 1958-1963, 2010.

[18] A. Etiemble, S. Rousselot, W. Guo, H. Idrissi, and L. Roué, "Influence of Pd addition on the electrochemical performance of MgeNieTieAl-based metal hydride for NieMH batteries," International Journal of Hydrogen Energy, vol. 38, no. 17, pp. 7169-7177, 2013.

[19] C.-H. Wang, F.-Y. Hung, T.-S. Lui, and L.-H. Chen, “The chargedischarge characteristics of woody carbon modified with $\mathrm{Fe}$ $3 \mathrm{O} 4$ nano phase using the hydrothermal method," Materials Transactions, vol. 51, no. 1, pp. 186-191, 2010.

[20] K.-L. Lee, J.-Y. Jung, S.-W. Lee, H.-S. Moon, and J.-W. Park, "Electrochemical characteristics of a-Si thin film anode for Liion rechargeable batteries," Journal of Power Sources, vol. 129, no. 2, pp. 270-274, 2004.

[21] Y. Liu, H. Pan, M. Gao, H. Miao, Y. Lei, and Q. Wang, "Function of $\mathrm{Al}$ on the cycling behavior of the $\mathrm{La}-\mathrm{Mg}-\mathrm{Ni}$-Co-type alloy electrodes," International Journal of Hydrogen Energy, vol. 33, no. 1, pp. 124-133, 2008.

[22] H. Song, Z. Cao, X. Chen et al., "Capacity fade of LiFePO4/ graphite cell at elecated temperature," Journal of Solid State Electrochemical, vol. 17, pp. 559-605, 2013.

[23] R. A. Guidotti and P. J. Masset, "Thermally activated ("thermal") battery technology. Part IV. Anode materials," Journal of Power Sources, vol. 183, no. 1, pp. 388-398, 2008. 

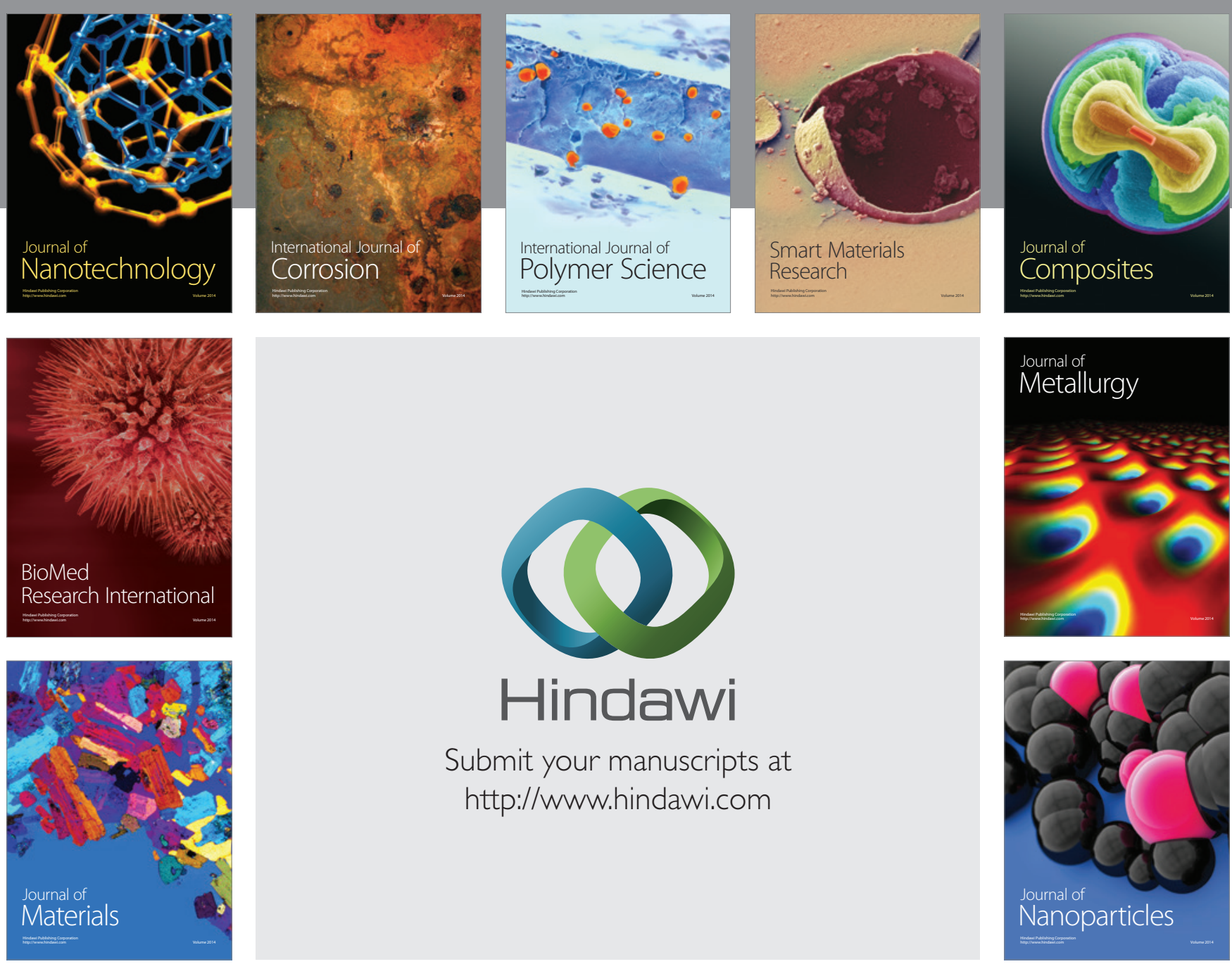

Submit your manuscripts at http://www.hindawi.com
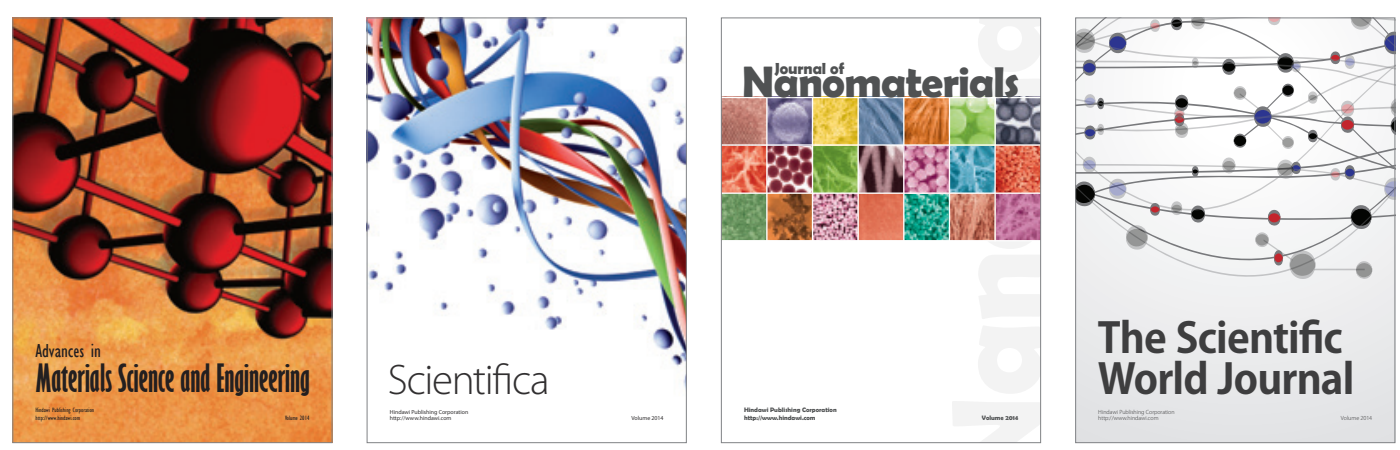

\section{The Scientific World Journal}
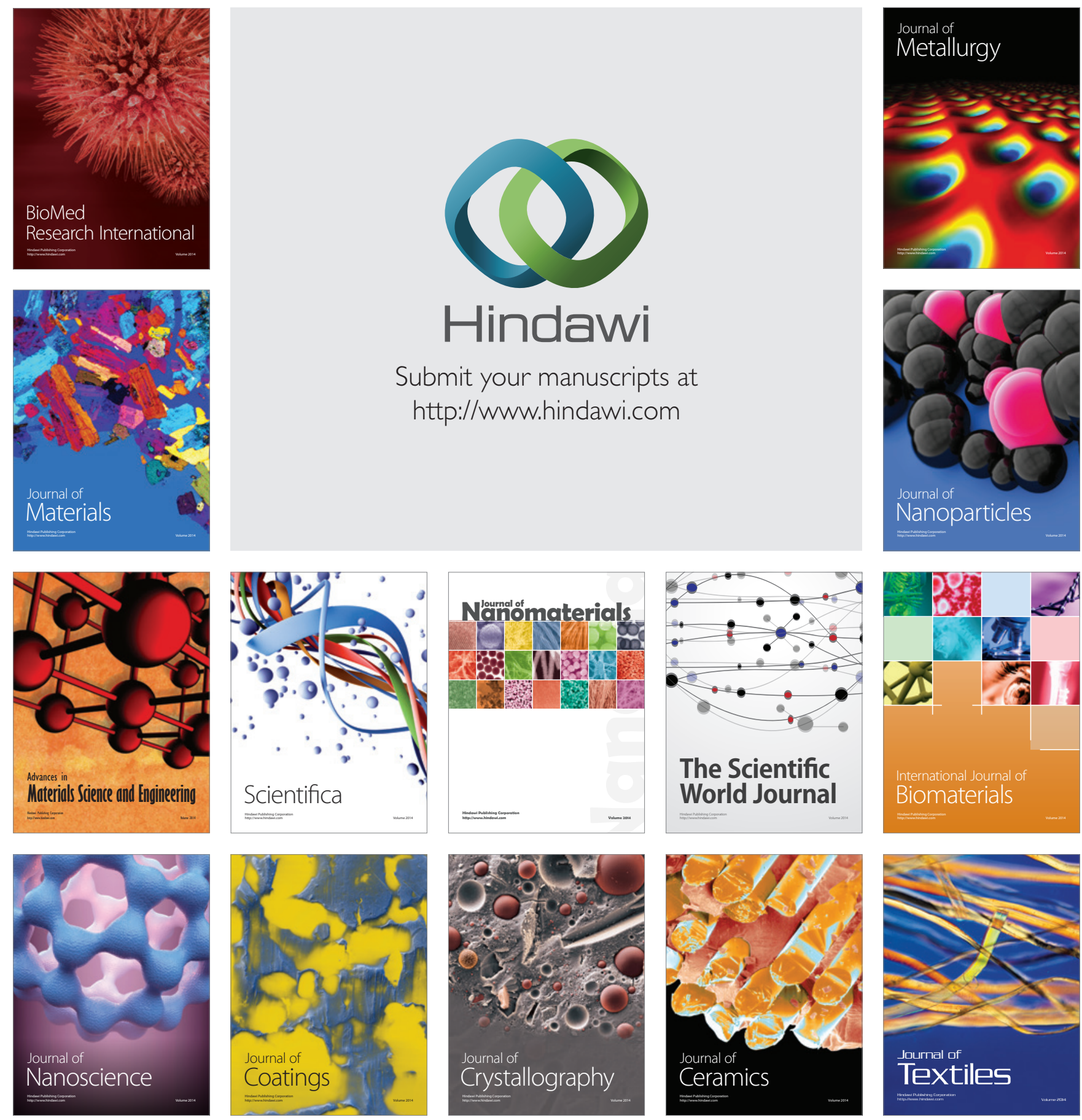